\title{
Temperature- and Pressure-Dependent Rate Coefficients for the HACA Pathways from Benzene to Naphthalene
}

\author{
Alexander M. Mebel, ${ }^{\mathrm{a}, *}$ Yuri Georgievskii, ${ }^{\mathrm{b}}$ Ahren W. Jasper, ${ }^{\mathrm{c}}$ and Stephen J. Klippenstein ${ }^{\mathrm{b}}$ \\ ${ }^{a}$ Department of Chemistry and Biochemistry, Florida International University, \\ Miami, Florida 33199, USA \\ ${ }^{b}$ Chemical Sciences and Engineering Division, Argonne National Laboratory, \\ Argonne, Illinois 60439, USA \\ ${ }^{c}$ Combustion Research Facility, Sandia National Laboratories, \\ Livermore, California 94551, USA
}

Corresponding Author: $\quad$ Name: Alexander M. Mebel

Street address: CP 332

Department: Department of Chemistry and Biochemisttry

University: Florida International University

University Address: 11200 SW $8^{\text {th }}$ Street, Miami, FL 33199, USA

Phone: +1-305-348-1945

E-mail: mebela@fiu.edu

Colloquium Topic Area: $\quad$ Soot, PAH \& Other Large Molecules

Total length: 6003 Words (Limit: 6200 words)

Main Text: 3437 words (MSWord word count)

Equations: 0

References: $\quad(31$ references +2$) \times(2.3$ lines $/$ reference $) \times(7.6$ words $/$ line $)=577$ words

Tables: $\quad 0$

Figure 1: $\quad[71 \mathrm{~mm}+10 \mathrm{~mm}] \times 2.2$ words $/ \mathrm{mm} \times 1$ column +34 words in caption $=212$ words

Figure 2: $\quad[37.6 \mathrm{~mm}+10 \mathrm{~mm}] \times 2.2$ words $/ \mathrm{mm} \times 1$ column +19 words in caption $=124$ words

Figure 3: $\quad[119 \mathrm{~mm}+10 \mathrm{~mm}] \times 2.2$ words $/ \mathrm{mm} \times 2$ columns +54 words in caption $=623$ words

Figure 4: $\quad[126 \mathrm{~mm}+10 \mathrm{~mm}] \times 2.2$ words $/ \mathrm{mm} \times 2$ columns +35 words in caption $=633$ words

Figure 5: $\quad[58 \mathrm{~mm}+10 \mathrm{~mm}] \times 2.2$ words $/ \mathrm{mm} \times 1$ column +19 words in caption $=169$ words

Figure 6: $\quad[85 \mathrm{~mm}+10 \mathrm{~mm}] \times 2.2$ words $/ \mathrm{mm} \times 1$ column +19 words in caption $=228$ words

Supplemental Material has been included in the submission of this paper.

Submitted to the $36^{\text {th }}$ International Symposium on Combustion, Seoul, Korea, July 31-August 5, 2016. 
Abstract. RRKM-Master Equation calculations have been performed to evaluate temperature- and pressure-dependent rate coefficients for acetylene addition reactions to the $\mathrm{C}_{6} \mathrm{H}_{5}, \mathrm{C}_{6} \mathrm{H}_{4} \mathrm{C}_{2} \mathrm{H}, \mathrm{C}_{6} \mathrm{H}_{5} \mathrm{C}_{2} \mathrm{H}_{2}$, and $\mathrm{C}_{6} \mathrm{H}_{4} \mathrm{C}_{2} \mathrm{H}_{3}$ radicals. These calculations indicate a strong pressure dependence for the role of various Hydrogen-Abstraction- $\mathrm{C}_{2} \mathrm{H}_{2}$-Addition (HACA) sequences for the formation of naphthalene from benzene. At atmospheric and lower pressures the $\mathrm{C}_{8} \mathrm{H}_{7}$ radicals, $\mathrm{C}_{6} \mathrm{H}_{4} \mathrm{C}_{2} \mathrm{H}_{3}$ and $\mathrm{C}_{6} \mathrm{H}_{5} \mathrm{C}_{2} \mathrm{H}_{2}$, cannot be stabilized above $1300 \mathrm{~K}$. As a result, both the Bittner-Howard HACA route, in which a second acetylene molecule adds to $\mathrm{C}_{6} \mathrm{H}_{5} \mathrm{C}_{2} \mathrm{H}_{2}$, and the modified Frenklach route, where a second $\mathrm{C}_{2} \mathrm{H}_{2}$ adds to the aromatic ring of $\mathrm{C}_{6} \mathrm{H}_{4} \mathrm{C}_{2} \mathrm{H}_{3}$ obtained by internal hydrogen abstraction, are unrealistic under low pressure flame conditions. At the higher pressures of some practical combustion devices (e.g., 100 atm) these routes may be operative. Naphthalene is predicted to be the main product of the $\mathrm{C}_{6} \mathrm{H}_{5} \mathrm{C}_{2} \mathrm{H}_{2}+\mathrm{C}_{2} \mathrm{H}_{2}$ and $\mathrm{C}_{6} \mathrm{H}_{4} \mathrm{C}_{2} \mathrm{H}_{3}+\mathrm{C}_{2} \mathrm{H}_{2}$ reactions in the entire 500-2500 $\mathrm{K}$ temperature range independent of pressure (ignoring the issues related to the instability of $\mathrm{C}_{8} \mathrm{H}_{7}$ species). Frenklach's original HACA route, where the second $\mathrm{C}_{2} \mathrm{H}_{2}$ molecule adds to the aromatic ring activated by intermolecular $\mathrm{H}$ abstraction from $\mathrm{C}_{8} \mathrm{H}_{6}$, involves the $\mathrm{C}_{6} \mathrm{H}_{4} \mathrm{C}_{2} \mathrm{H}+\mathrm{C}_{2} \mathrm{H}_{2}$ reaction, which is shown to predominantly form dehydrogenated species with a naphthalene core (naphthyl radicals or naphthynes) at $T<2000 \mathrm{~K}$ and diethynylbenzene at higher temperatures. The temperature and pressure dependence of rate coefficients for the various reaction channels has been analyzed and the results clearly demonstrate the importance of pressure for the reaction outcome. Thus, one must use caution when using low-pressure flame studies to validate PAH mechanisms for use in broader ranges of pressure.

Keywords: Hydrogen-Abstraction- $\mathrm{C}_{2} \mathrm{H}_{2}$-Addition (HACA); Naphthalene; Reaction mechanisms; PAH; Soot 


\section{Introduction}

A detailed understanding of the mechanism for the formation and growth of polycyclic aromatic hydrocarbons (PAHs) remains one of the central problems in combustion. PAHs are among the most abundant pollutants, exerting a great impact on our environment and health. In combustion environments, simple PAHs, such as naphthalene, indene, phenanthrene, and pyrene, are involved in a build-up process that leads to larger PAHs, fullerenes, bowl-shaped nanostructures, and solid-phase species including carbonaceous dust, graphene particles, and soot [1]. There are many possible pathways for PAH formation and growth in hydrocarbon flames arising from the great variety of molecules and radicals that are present in significant concentrations [2-4]. Numerous detailed kinetic models have been developed and explored for the formation of simple PAHs from smaller ring and chain hydrocarbons [see, e.g., 2-11]. However, the rate constants employed for most of the reactions, including many of the

most important ones, are generally not reliable and lack any description of the pressure dependence of the rate constants. Furthermore, there is a great lack of information on the branching between different products, which is generally highly dependent on temperature and pressure.

How can these major deficiencies be addressed? The a priori RRKM-Master Equation (RRKM-ME) theoretical approach is capable of computing temperature- and pressure-dependent rate coefficients with 'kinetic accuracy', i.e., with accuracies comparable to that of experiment [12]. The recently developed Master Equation System Solver (MESS) program [13], which uses the chemically significant eigenvalue method to relate the eigensolutions of the ME to the set of elementary rate coefficients for multiwell and multichannel potential energy surfaces (PESs) [14], greatly facilitates the evaluation of temperature- and pressure-dependent rate coefficients for complex reactions. Thus, we have initiated a systematic research project aimed at the generation of reliable rate coefficients for use in the testing of various mechanisms of PAH formation and growth. Our goal is to first explore all possible pathways to the simplest two-ring 
PAHs, naphthalene and indene, and then eventually extend the studies to further PAH growth as well as to PAH oxidation.

The present work begins the methodical investigation of the formation of naphthalene. Eventually we plan to consider all possible pathways to naphthalene, but we start our studies from the HydrogenAbstraction- $\mathrm{C}_{2} \mathrm{H}_{2}$-Addition (HACA) mechanism originating from benzene, the mechanism that is not only arguably best known but also best studied theoretically in terms of the related PESs. Introduced by Frenklach and co-workers [15-20], HACA represents a repetitive sequence of two principal reaction types: the abstraction of a hydrogen atom from the reacting hydrocarbon by a radical followed by the addition(s) of acetylene molecules to the radical site formed in the previous H-abstraction step. The production of a higher $\mathrm{PAH}$, containing an extra aromatic ring in its core, can be accomplished by a ring closure ensuing the $\mathrm{C}_{2} \mathrm{H}_{2}$ addition(s). Two alternative HACA pathways for the sequential additions of two $\mathrm{C}_{2} \mathrm{H}_{2}$ were proposed by Frenklach et al. [15-20] and by Bittner and Howard [21]. In Frenklach's route, the second acetylene adds to the aromatic ring activated by either a conventional or an internal $[19,20]$ hydrogen abstraction mechanism, whereas in Bittner-Howard's route, the second acetylene molecule adds to the first one.

Several high-level ab initio studies of some important HACA steps have been carried out in recent years [22-24]. However, except for the $\mathrm{C}_{6} \mathrm{H}_{5}+\mathrm{C}_{2} \mathrm{H}_{2}$ reaction [23] and early AM1/RRKM calculations [17], rate coefficient calculations were limited to the high-pressure (HP) limit. Since rate coefficients for the bimolecular direct $\mathrm{H}$ abstraction reactions are reasonably well established and are independent of pressure, we focus on acetylene addition steps to radicals along the HACA sequences from phenyl $\left(\mathrm{C}_{6} \mathrm{H}_{5}\right)$ to naphthalene $\left(\mathrm{C}_{10} \mathrm{H}_{8}\right)$. We report temperature- and pressure-dependent rate coefficients and product branching ratios for the reactions involved and discuss the potential relevance and importance of HACA under different combustion conditions. 


\section{Calculation Methods}

Temperature- and pressure-dependent phenomenological rate coefficients were computed from the solutions to the one-dimensional ME employing the MESS program [13,14]. These rate coefficient calculations were based upon PESs and molecular parameters computed at the G3(MP2,CC)//B3LYP/6$311 \mathrm{G}^{* *}$ level of theory as published earlier [24]. Several additional, potentially important reaction channels were included, which were not considered before. For these channels, the same theoretical level was employed. The reason for the use of the G3(MP2,CC)//B3LYP energetics is twofold. First, this approach provides average absolute deviation for energies of hydrocarbons (from the G2/97 test set) of $0.71 \mathrm{kcal} / \mathrm{mol}$. At $1000 \mathrm{~K}$, an error in $\Delta \mathrm{E}$ of $0.71 \mathrm{kcal} / \mathrm{mol}$ would result in $\sim 35 \%$ error in the rate coefficient. By $1500 \mathrm{~K}$ the error in the rate coefficient decreases to $\sim 25 \%$, which is less than the uncertainties arising from other aspects of the calculation. Second, while more accurate ab initio calculations, like CCSD(T)-F12/CBS//B2PLYPD3 can be accomplished for C10 systems, the current literature contains a wealth of information on the potential energy surfaces related to the formation of the first aromatic ring and two- and three-ring PAHs typically computed at a G3-type level of theory, including CBS-QB3. In order to convert the available data on the PES to physics-based temperature- and pressure-dependent rate coefficients, it is our strategy to utilize these available data and provide the rate coefficients for kinetic modeling. Once kinetic modeling identifies the most critical reactions, more accurate ab initio and theoretical kinetics calculations can be performed for further improvement.

Pressure dependence was modeled in the ME using the single-exponential-down model [25], with collision efficiencies and Lennard-Jones parameters calculated using newly-fitted potential energy surfaces, classical trajectories [26], and the "one-dimensional optimization" method [27], respectively. The strategies used here have been described in more detail elsewhere [28]. Results for $\mathrm{C}_{6} \mathrm{H}_{5} \mathrm{C}_{2} \mathrm{H}_{2} / \mathrm{N}_{2}$, 
$\mathrm{C}_{6} \mathrm{H}_{5} \mathrm{C}_{2} \mathrm{H}_{2} / \mathrm{Ar}$, and $\mathrm{C}_{10} \mathrm{H}_{7} / \mathrm{Ar}$ were found to agree with one another within $10 \%$. The similarity of Ar and $\mathrm{N}_{2}$ and the negligible size-dependence for targets with several heavy atoms is consistent with past work [26]. The $\mathrm{C}_{10} \mathrm{H}_{7} / \mathrm{Ar}$ parameters were used for the larger systems considered here. The uncertainty in the Lennard-Jones parameters is unlikely to be the dominant source of error in the present calculations, in view of the uncertainty in the relative energies discussed above.

The Rigid-Rotor, Harmonic-Oscillator (RRHO) model was generally utilized in the calculation of the densities of states and partition functions for the molecular complexes and the number of states for the transition states. Tunneling corrections were included using Eckart potentials. Soft normal modes were visually inspected and those corresponding to uncoupled internal rotations of a certain group of atoms were treated as one-dimensional hindered rotors, while those corresponding to coupled internal rotations of two groups were treated as two-dimensional rotors; torsional potentials were obtained from relaxed PES scans at the B3LYP/6-311G** level of theory. The detailed information concerning the groups involved and rotors' potentials is available in the Supplemental Material with the input file for the RRKM-ME calculations.

For reaction steps occurring via relatively low barriers (at least in one direction), such as all $\mathrm{C}_{2} \mathrm{H}_{2}$ additions and some $\mathrm{H}$ atom eliminations, RRHO-based variational transition state theory (VTST) calculations were performed. These VTST calculations employed G3(MP2,CC)//B3LYP/6-311G** calculated energies along the intrinsic reaction coordinate (IRC) minimal energy path (MEP). The details of the MEP scans are available in the Supplemental Material with the input file for RRKM-ME calculations and plots of PESs from IRC calculations. For the barrierless $\mathrm{H}$ elimination steps from naphthyl radicals, the transition state flux was evaluated within variable reaction coordinate-transition state theory (VRC-TST) [29] employing direct CASPT2(3,3)/cc-pVDZ energies and a one-dimensional correction for geometry relaxation and for more accurate CASPT2 $(9,9)$ spin-splitting + RUCCSD(T)quartet MEP energies evaluated at the complete basis set (CBS) limit. The choice of this approach was 
determined by our detailed study of rate constants for $\mathrm{H}$ addition to aromatic alkynes, which will be published elsewhere. The results of this study indicate that the accurate description of the long-range potential needed to obtain accurate rate coefficients for the $\mathrm{H}$ addition and hence the rate coefficients for the inverse reaction of $\mathrm{H}$ loss from naphthyl radicals requires at least the CASPT2 level of theory with one-dimensional corrections for larger active space and extrapolation to the CBS limit.

\section{Results and Discussion}

The sequences of reactions involved in various HACA related mechanisms are depicted schematically in Fig. 1 [24]. Each of these pathways begins with the addition of acetylene to the phenyl radical. The pathways then branch out through different sequences of internal and external $\mathrm{H}$ abstractions, $\mathrm{C}_{2} \mathrm{H}_{2}$ additions, and $\mathrm{H}$ losses. In the following subsections we consider master equation based theoretical predictions for the temperature and pressure dependent kinetics of each of the relevant reaction systems. Modified Arrhenius fits to our calculated rate coefficients are provided in the Supplemental Material. Comparisons between the present rate predictions and those of Wang and Frenklach [17] are also provided therein. We focus on pressures of 30 Torr, 1, 10 and 100 atm as representative of low pressure flame speciation studies, flame speed experiments (at low and high P), and practical engine conditions, respectively. Note that the present analyses require some generalizations of the proposed pathways due to the well skipping nature of the true kinetics. For example, the $\mathrm{C}_{6} \mathrm{H}_{5}+$

$\mathrm{C}_{2} \mathrm{H}_{2} \rightarrow \mathrm{C}_{8} \mathrm{H}_{7} \rightarrow \mathrm{C}_{8} \mathrm{H}_{6}+\mathrm{H}$ sequence of the Frenklach mechanism should generally be replaced with a single reaction step, $\mathrm{C}_{6} \mathrm{H}_{5}+\mathrm{C}_{2} \mathrm{H}_{2} \rightarrow \mathrm{C}_{8} \mathrm{H}_{6}+\mathrm{H}$. 


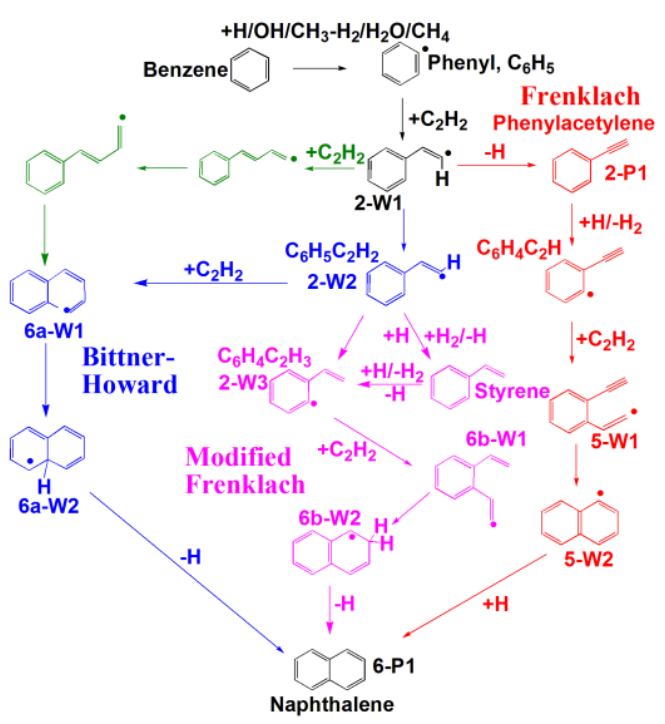

Figure 1. Schematic illustration of the Frenklach (red), modified Frenklach (pink), and Bittner-Howard (blue) HACA routes. The path in green is part of the original Bittner-Howard mechanism that was subsequently found to have a high barrier.

\section{$3.1 \mathrm{C}_{6} \mathrm{H}_{5}+\mathrm{C}_{2} \mathrm{H}_{2}$}

The PES depicted in Fig. 2 provides the stationary point energies for only the most relevant channels in the phenyl + acetylene reaction, as concluded in a more detailed study by Tokmakov and Lin [23]. $\mathrm{C}_{2} \mathrm{H}_{2}$ addition to phenyl leads to the formation of a trans $\mathrm{C}_{6} \mathrm{H}_{5} \mathrm{C}_{2} \mathrm{H}_{2}$ radical (W1), which can rearrange to a cis $\mathrm{C}_{6} \mathrm{H}_{5} \mathrm{C}_{2} \mathrm{H}_{2}$ isomer (W2) and then to $\mathrm{C}_{6} \mathrm{H}_{4} \mathrm{C}_{2} \mathrm{H}_{3}$ (W3), by a 1,4-H shift. Alternatively, W1 can lose an $\mathrm{H}$ atom to form phenylacetylene (P1). The cis-trans isomerization is more rapid than internal energy relaxation under all relevant conditions and $\mathrm{W} 1$ and $\mathrm{W} 2$ are considered as a single merged species (W1+W2) in the kinetic analysis. Thus, the $\mathrm{C}_{6} \mathrm{H}_{5}+\mathrm{C}_{2} \mathrm{H}_{2}$ reaction can either produce stabilized $\mathrm{C}_{8} \mathrm{H}_{7}$ radicals (W1+W2 or W3) or $\mathrm{C}_{6} \mathrm{H}_{5} \mathrm{C}_{2} \mathrm{H}+\mathrm{H}$. 


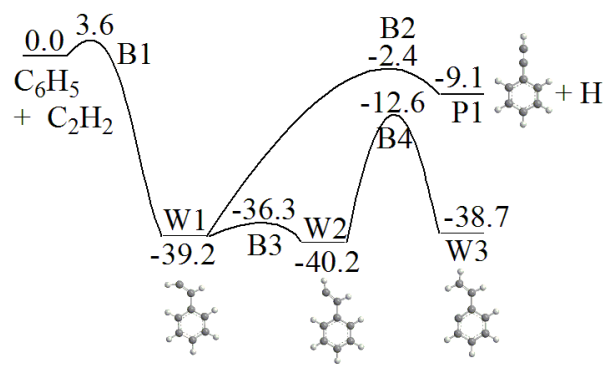

Figure 2. Schematic diagram of the G3(MP2,CC) stationary point energies for the kinetically relevant channels in the $\mathrm{C}_{6} \mathrm{H}_{5}+\mathrm{C}_{2} \mathrm{H}_{2}$ reaction.

As seen in Fig. 3, the overall rate coefficient for the $\mathrm{C}_{6} \mathrm{H}_{5}+\mathrm{C}_{2} \mathrm{H}_{2}$ reaction shows a rather weak pressure-dependence. The HP limit rate coefficient exhibits typical near Arrhenius behavior increasing from $4.0 \times 10^{-14} \mathrm{~cm}^{3}$ molecule $\mathrm{s}^{-1}$ at $500 \mathrm{~K}$ to $8.8 \times 10^{-12} \mathrm{~cm}^{3}$ molecule $\mathrm{s}^{-1}$ at $2500 \mathrm{~K}$. At $\sim 650 \mathrm{~K}$ the rate coefficients begin to show a pressure dependent fall-off, with an increasing deviation from the HP limit as the temperature increases. At the highest temperatures, the overall rate coefficient becomes more or less pressure independent, as it becomes difficult to stabilize the wells. The largest $k(\mathrm{HP}) / k(p)$ ratio, 2.2, is found at the highest temperature considered, $2500 \mathrm{~K}$. The largest difference between finite-pressure rate coefficients is found around $1375 \mathrm{~K}$ where $k(100 \mathrm{~atm}) / k(30$ Torr $)=1.78$.

The overall rate coefficients calculated here are in reasonable agreement with the previous experimental and theoretical data. For instance, at 20 Torr $k(500 \mathrm{~K})$ exceeds the value reported by Lin and coworkers [30] by 63\%, but the values at $T=1000-1330 \mathrm{~K}$ measured by Fahr and Stein [31] agree with the present results to within 13-41\%, while showing a steeper $T$-dependence. It should be noted that the previous theoretical calculations by Tokmakov and Lin [23] did not show significant pressure dependence (Fig. 3). The deviation of the rate constant from experiment at $500 \mathrm{~K}$ corresponds to a 0.5 $\mathrm{kcal} / \mathrm{mol}$ error in the barrier height, which is within the error bars for our calculations of relative energies. At higher temperatures (1000-1330 K), experimental rate constants were derived from fitting to a complex mechanism, and we expect that the theoretical and experimental error bars overlap here. 

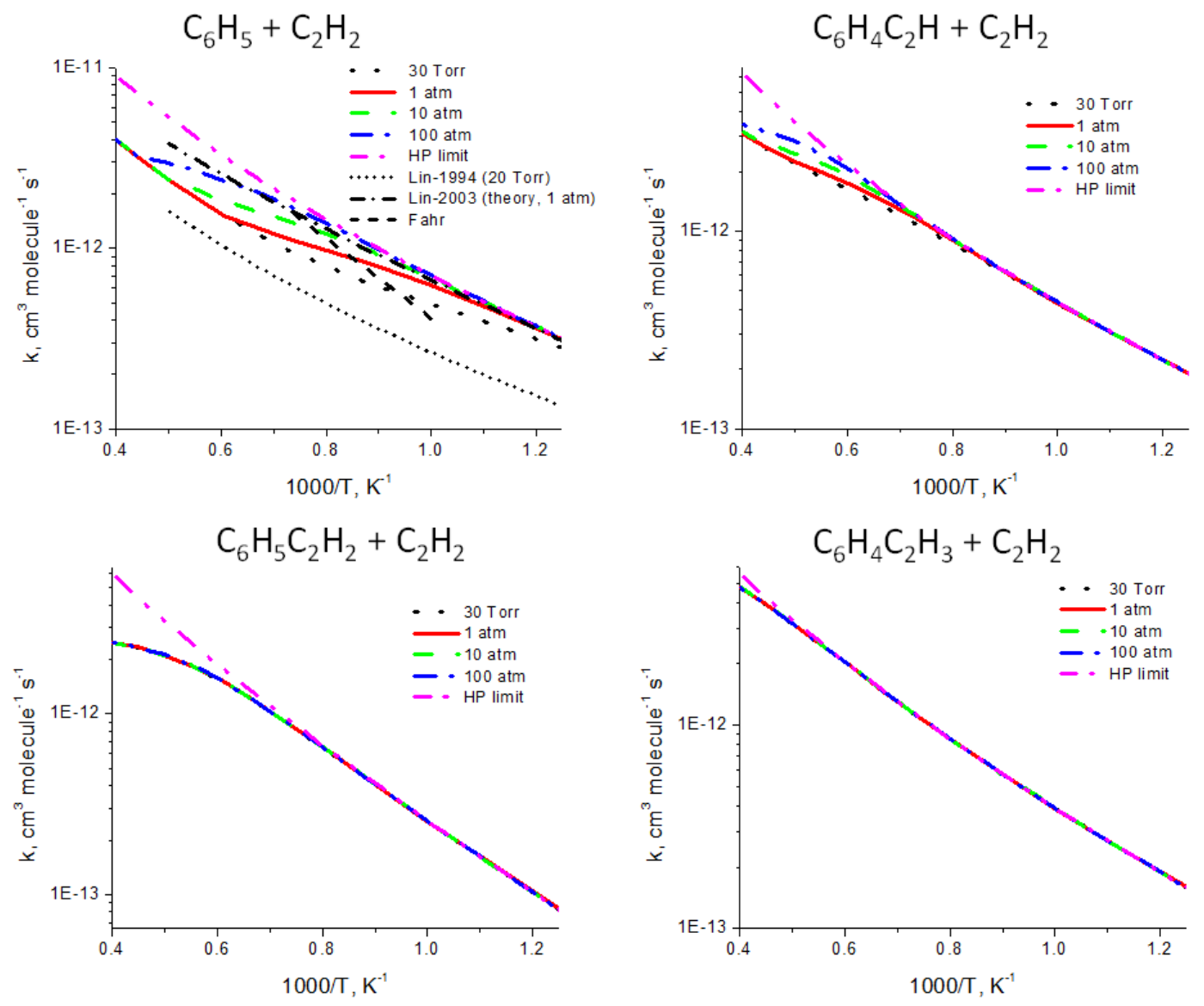

Figure 3. Plot of the predicted temperature and pressure dependence of the overall rate coefficient for the reaction of $\mathrm{C}_{2} \mathrm{H}_{2}$ with $\mathrm{C}_{6} \mathrm{H}_{5}, \mathrm{C}_{6} \mathrm{H}_{4} \mathrm{C}_{2} \mathrm{H}, \mathrm{C}_{6} \mathrm{H}_{5} \mathrm{C}_{2} \mathrm{H}_{2}$, and $\mathrm{C}_{6} \mathrm{H}_{4} \mathrm{C}_{2} \mathrm{H}_{3}$. For the $\mathrm{C}_{6} \mathrm{H}_{5}+\mathrm{C}_{2} \mathrm{H}_{2}$ reaction, prior experimental results of Lin and coworkers [30] and Fahr and Stein [31] and theoretical predictions of Tokmakov and Lin [23] are also depicted.

The pressure effects are much stronger for the product branching ratios (cf. Fig. 4). The competition is between stabilization of the $\mathrm{C}_{8} \mathrm{H}_{7}$ radicals (to $\mathrm{W} 1+\mathrm{W} 2$ and $\mathrm{W} 3$ separately at low temperature or to $\mathrm{W} 1+\mathrm{W} 2+\mathrm{W} 3$ at higher temperature) and $\mathrm{H}$ loss producing phenylacetylene (P1). For low pressure flame conditions ( $p=30$ Torr) stabilization prevails only at low temperatures, with the formation of P1 already dominant by $1000 \mathrm{~K}$. At $1100 \mathrm{~K}$ the wells equilibrate rapidly and there is effectively only a single joint species (W1+W2+W3, which is labeled as W3 in the plot). Above $1300 \mathrm{~K}$ the dissociation of $\mathrm{W} 1+\mathrm{W} 2+\mathrm{W} 3$ occurs more rapidly than internal energy relaxation, the wells are no longer chemically 
stable, and the stabilization branching goes to 0 . This result effectively rules out the Bittner-Howard and modified Frenklach HACA routes under low-pressure flame conditions because their second steps involve addition of another $\mathrm{C}_{2} \mathrm{H}_{2}$ molecule to the unstable $\mathrm{C}_{6} \mathrm{H}_{5} \mathrm{C}_{2} \mathrm{H}_{2}$ and $\mathrm{C}_{6} \mathrm{H}_{4} \mathrm{C}_{2} \mathrm{H}_{3}$ radicals, respectively. In contrast, the production of phenylacetylene $+\mathrm{H}$ now occurs in one chemical step, suggesting a possibly enhanced role for the original HACA mechanism of Frenklach.

For $p=1 \mathrm{~atm}, \mathrm{~W} 1+\mathrm{W} 2+\mathrm{W} 3$ persists to somewhat higher temperatures (i.e., $1650 \mathrm{~K}$ ). By $100 \mathrm{~atm}$, the wells maintain their stability to $2250 \mathrm{~K}$. Furthermore, the branching to phenylacetylene $+\mathrm{H}$ does not exceed the total well stabilization branching until about $2000 \mathrm{~K}$. Thus, it appears that at the pressures of practical combustion devices, the Bittner-Howard and modified Frenklach HACA routes may be significant. However, as illustrated in Fig. S1 of the supplementary material, the equilibrium between $\mathrm{C}_{6} \mathrm{H}_{5}+\mathrm{C}_{2} \mathrm{H}_{2}$ and the wells generally shifts to favor $\mathrm{C}_{6} \mathrm{H}_{5}+\mathrm{C}_{2} \mathrm{H}_{2}$ at temperatures below $1500 \mathrm{~K}$. Thus, the reaction will generally operate in reverse. 

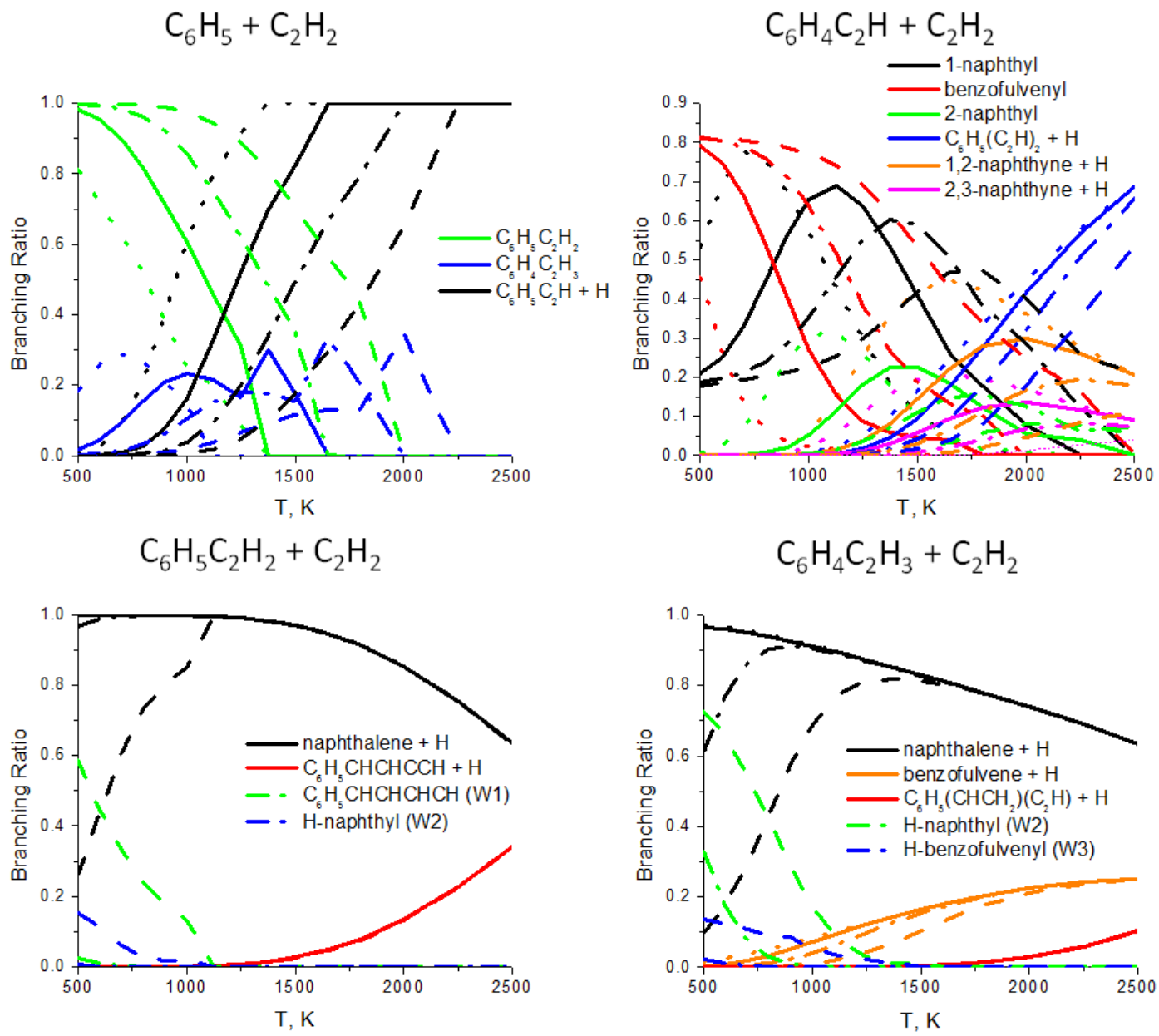

Figure 4. Plot of the predicted temperature dependence of the branching ratios for the reaction of $\mathrm{C}_{2} \mathrm{H}_{2}$ with $\mathrm{C}_{6} \mathrm{H}_{5}, \mathrm{C}_{6} \mathrm{H}_{4} \mathrm{C}_{2} \mathrm{H}, \mathrm{C}_{6} \mathrm{H}_{5} \mathrm{C}_{2} \mathrm{H}_{2}$, and $\mathrm{C}_{6} \mathrm{H}_{4} \mathrm{C}_{2} \mathrm{H}_{3}$ at pressures of 30 Torr (dotted), 1 (solid), 10 (dasheddotted), and $100 \mathrm{~atm}$ (dashed).

\section{$3.2 \mathrm{C}_{6} \mathrm{H}_{4} \mathrm{C}_{2} \mathrm{H}+\mathrm{C}_{2} \mathrm{H}_{2}$}

Consider now the $\mathrm{C}_{6} \mathrm{H}_{4} \mathrm{C}_{2} \mathrm{H}+\mathrm{C}_{2} \mathrm{H}_{2}$ reaction of Frenklach's original sequence, which follows activation of phenylacetylene by $\mathrm{H}$ abstraction at the ortho position of the ring. As seen in Fig. 5, the reaction mechanism is more complex than was assumed in prior studies [22,24]. $\mathrm{C}_{2} \mathrm{H}_{2}$ addition to $\mathrm{C}_{6} \mathrm{H}_{4} \mathrm{C}_{2} \mathrm{H}$ leads to the formation of $\mathrm{C}_{6} \mathrm{H}_{4}\left(\mathrm{C}_{2} \mathrm{H}\right)\left(\mathrm{C}_{2} \mathrm{H}_{2}\right)$ (W1), which either loses an $\mathrm{H}$ atom to form diethynylbenzene (P1) or undergoes a six- or five-member ring closure to form 1-naphthyl (W2) or a 
benzofulvenyl radical (W3), respectively. Ensuing $\mathrm{H}$ migrations can produce 2-naphthyl (W4) or different isomers of benzofulvenyl (W5-W7), whereas H eliminations from 1- and 2-naphthyls can form 1,2-naphthyne (1,2-didehydronaphthalene) and 2,3-naphthyne (2,3-didehydronaphthalene). $\mathrm{H}$ losses from benzofulvenyl radicals yielding didehydrobenzofulvenes are clearly not competitive. Since the naphthyl and benzofulvenyl radicals reside in much deeper potential wells in the $\mathrm{C}_{6} \mathrm{H}_{4} \mathrm{C}_{2} \mathrm{H}+\mathrm{C}_{2} \mathrm{H}_{2}$ reaction as compared to the $\mathrm{C}_{8} \mathrm{H}_{7}$ radicals with respect to $\mathrm{C}_{6} \mathrm{H}_{5}+\mathrm{C}_{2} \mathrm{H}_{2}$, collisional stabilization should play a more important role and there is no problem with reaction reversal. Meanwhile, the $\mathrm{H}$ elimination products, naphthynes and diethynylbenzene, are sufficiently exothermic and also can contribute. Therefore, we anticipate a strong dependence of the reaction outcome on both temperature and pressure.

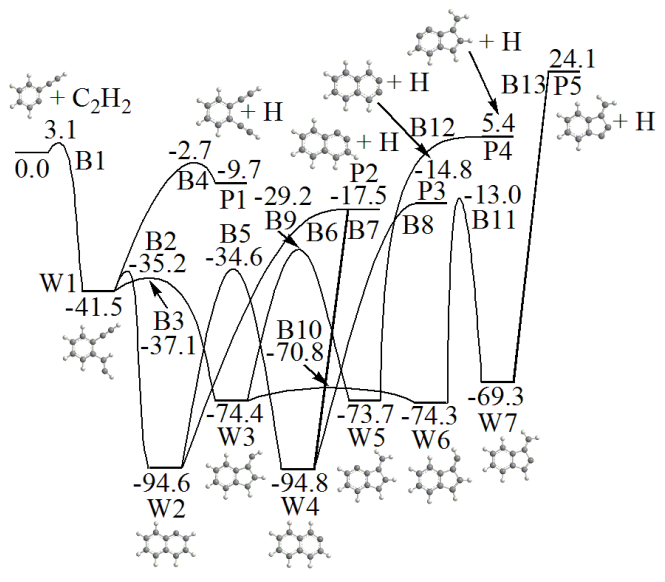

Figure 5. Schematic diagram of the G3(MP2,CC) stationary point energies for the kinetically relevant channels in the $\mathrm{C}_{6} \mathrm{H}_{4} \mathrm{C}_{2} \mathrm{H}+\mathrm{C}_{2} \mathrm{H}_{2}$ reaction.

Here, the pressure dependence for the overall rate coefficients is moderate (cf. Fig. 3), with fall-off starting at $T \sim 1200 \mathrm{~K}$. The maximum deviation between the $100 \mathrm{~atm}$ and 30 Torr finite pressure rate coefficients is 1.30 . Thus, for this reaction it is reasonable to represent the overall rate coefficient as pressure independent, using the $10 \mathrm{~atm}$ master equation results, for example. Nevertheless, it is worth noting that the falloff from the HP limit is still significant, reaching a factor of 2.0 for the 30 Torr results at $2500 \mathrm{~K}$. This deviation from the high pressure limit indicates that at high temperatures half of the entrance channel flux returns to reactants. 
There are a large number of stable products formed in the $\mathrm{C}_{6} \mathrm{H}_{4} \mathrm{C}_{2} \mathrm{H}+\mathrm{C}_{2} \mathrm{H}_{2}$ reaction and the branching between them is strongly dependent on both temperature and pressure (cf. Fig. 4). At low temperatures, the dominant products are a variety of bicyclic rings; first benzofulvenyl (W3), then 1naphthyl (W2), and 2-naphthyl (W4). At higher temperatures, dissociations to diethynylbenzene (P1), 1,2-naphthyne (P2), and 2,3-naphthyne (P3) become significant, with the formation of diethynylbenzene generally dominant above $2000 \mathrm{~K}$. For low-pressure flame conditions, the products are almost solely $\mathrm{H}$ + the two naphthynes (P2 and P3). More generally, in the key temperature range from 1500 to $2000 \mathrm{~K}$, various forms of the naphthalene cores (naphthyls and naphthynes) are the dominant products. Thus, the significance of the original Frenklach mechanism to naphthalene formation will be strongly dependent on the competition between conversion of these naphthalene cores to naphthalene (via $\mathrm{H}$ additions or abstractions from other species) and their dissociation or bimolecular reactions. The diethynylbenzene formed at higher temperatures may also be converted to naphthyls or naphthynes by H-assisted isomerization.

\section{$3.3 \mathrm{C}_{8} \mathrm{H}_{7}+\mathrm{C}_{2} \mathrm{H}_{2}$}

At high pressures the $\mathrm{C}_{8} \mathrm{H}_{7}$ radicals are stable enough to allow for their further reaction with $\mathrm{C}_{2} \mathrm{H}_{2}$ yielding naphthalene. As seen in Fig. 6, acetylene addition to 1-styryl forms $\mathrm{C}_{6} \mathrm{H}_{5} \mathrm{CHCHCHCH}$ (W1), which easily ring-closes to the 8a-H-naphthyl radical (W2) and then loses the extra hydrogen. Alternatively, $\mathrm{H}$ elimination from $\mathrm{W} 1 \mathrm{can}$ form a one-ring $\mathrm{C}_{6} \mathrm{H}_{5} \mathrm{CHCHCCH}$ product $(\mathrm{P} 2)$. The acetylene addition mechanism is more complex for $o$-vinylphenyl. The addition initially produces $\mathrm{C}_{6} \mathrm{H}_{4}\left(\mathrm{CHCH}_{2}\right)(\mathrm{CHCH})$, which may undergo either six-member ring closure to 2-H-naphthyl or fivemember ring closure to an H-benzofulvenyl radical. The latter can dissociate to benzofulvene or interconvert to 2-H-naphthyl. Also, $\mathrm{H}$ eliminations from the initial $\mathrm{C}_{6} \mathrm{H}_{4}\left(\mathrm{CHCH}_{2}\right)(\mathrm{CHCH})$ complex and 2-H-naphthyl lead to 1-ethynyl-2-vinylbenzene (P3) and naphthalene, respectively. 
At finite pressures, the total rate coefficients for the $\mathrm{C}_{6} \mathrm{H}_{4} \mathrm{C}_{2} \mathrm{H}_{3}+\mathrm{C}_{2} \mathrm{H}_{2}$ reaction are factors of 1.264.35 greater than those for $\mathrm{C}_{6} \mathrm{H}_{5} \mathrm{C}_{2} \mathrm{H}_{2}+\mathrm{C}_{2} \mathrm{H}_{2}$, with the difference increasing at low temperatures, but otherwise they show similar behavior. Rate coefficients for both reactions are practically independent of pressure and the fall-off from the HP limit is maximal at $2500 \mathrm{~K}$; factors of 2.93 and 1.15 for $\mathrm{C}_{6} \mathrm{H}_{5} \mathrm{C}_{2} \mathrm{H}_{2}$ $+\mathrm{C}_{2} \mathrm{H}_{2}$ and $\mathrm{C}_{6} \mathrm{H}_{4} \mathrm{C}_{2} \mathrm{H}_{3}+\mathrm{C}_{2} \mathrm{H}_{2}$, respectively. Product branching ratios are found to be nearly pressureindependent above $1000 \mathrm{~K}\left(\mathrm{C}_{6} \mathrm{H}_{5} \mathrm{C}_{2} \mathrm{H}_{2}+\mathrm{C}_{2} \mathrm{H}_{2}\right)$ and $1500 \mathrm{~K}\left(\mathrm{C}_{6} \mathrm{H}_{4} \mathrm{C}_{2} \mathrm{H}_{3}+\mathrm{C}_{2} \mathrm{H}_{2}\right)$ (Fig. 4), but at lower temperatures and higher pressures some $\mathrm{C}_{10} \mathrm{H}_{9}$ intermediates can be stabilized. At $T>1000 \mathrm{~K}$, $\mathrm{C}_{6} \mathrm{H}_{5} \mathrm{C}_{2} \mathrm{H}_{2}+\mathrm{C}_{2} \mathrm{H}_{2}$ produces only naphthalene and $\mathrm{C}_{6} \mathrm{H}_{5} \mathrm{CHCHCCH}$ with the branching ratio for the former decreasing from 100 to $63 \%$ at $2500 \mathrm{~K}$. Above $1500 \mathrm{~K}$, the $\mathrm{C}_{6} \mathrm{H}_{4} \mathrm{C}_{2} \mathrm{H}_{3}+\mathrm{C}_{2} \mathrm{H}_{2}$ reaction forms naphthalene (82-63\%), benzofulvene (10-25\%), and up to $10 \%$ of $\mathrm{C}_{6} \mathrm{H}_{4}\left(\mathrm{CHCH}_{2}\right)(\mathrm{CCH})$. Thus, naphthalene is anticipated to be the dominant product of acetylene addition to these $\mathrm{C}_{8} \mathrm{H}_{7}$ radicals under typical combustion conditions.

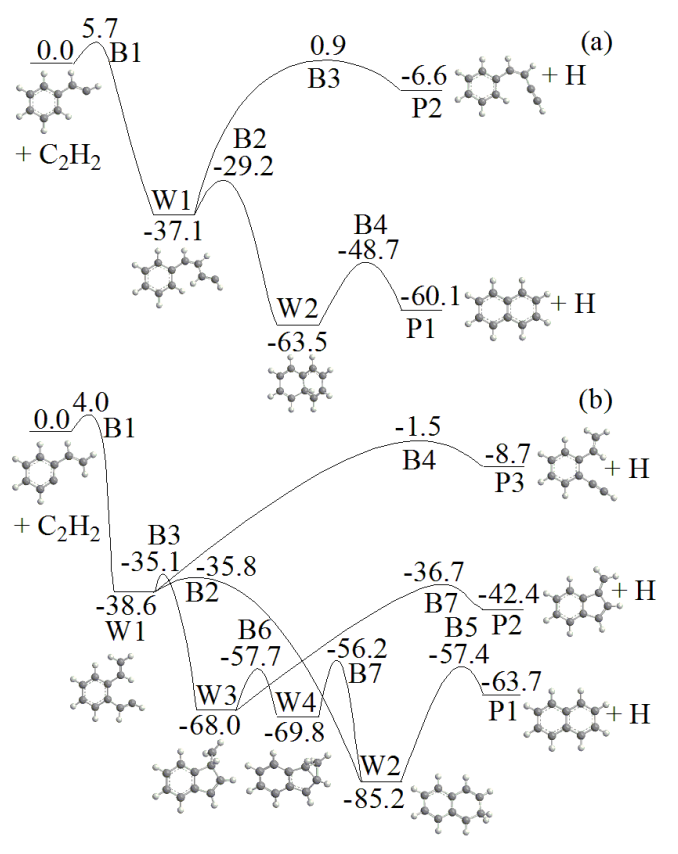

Figure 6. Schematic diagram of the G3(MP2,CC) stationary point energies for the kinetically relevant channels in two $\mathrm{C}_{8} \mathrm{H}_{7}+\mathrm{C}_{2} \mathrm{H}_{2}$ reactions. 


\section{Concluding Remarks}

The present calculations clearly illustrate the importance of considering the pressure dependence of the kinetics of naphthalene formation reactions. In each case the predicted total rate constants, although only weakly dependent on pressure for finite pressures, deviate substantially from the high pressure limit. More importantly, the branching amongst various products is strongly dependent on pressure. It is clear that if the relative product yields were measured at low pressures, as in typical flow reactor experiments, low pressure flame speciation studies, or under single-collision conditions in crossed molecular beams, the results would bear little resemblance to the product distribution at atmospheric and higher pressures. Nevertheless, such experiments are of great value in calibrating properly pressure dependent models.

While our main goal is to provide reliable temperature- and pressure-dependent rate coefficients for kinetic modeling of PAH growth in flames, the present calculations already shed some light on the potential importance of the HACA mechanism for the formation of naphthalene from benzene. For instance, it is evident that the $\mathrm{C}_{8} \mathrm{H}_{7}$ radicals, $\mathrm{C}_{6} \mathrm{H}_{4} \mathrm{C}_{2} \mathrm{H}_{3}$ and $\mathrm{C}_{6} \mathrm{H}_{5} \mathrm{C}_{2} \mathrm{H}_{2}$, are unstable species and cannot be stabilized at atmospheric pressure (or lower) for temperatures of $1500 \mathrm{~K}$ and higher. This makes both the Bittner-Howard and the modified Frenklach HACA routes unrealistic under typical low-pressure flame conditions. At higher pressures the $\mathrm{C}_{8} \mathrm{H}_{7}$ radicals may contribute significantly to the formation of naphthalene because it is the main product of the $\mathrm{C}_{6} \mathrm{H}_{4} \mathrm{C}_{2} \mathrm{H}_{3}+\mathrm{C}_{2} \mathrm{H}_{2}$ and $\mathrm{C}_{6} \mathrm{H}_{5} \mathrm{C}_{2} \mathrm{H}_{2}+\mathrm{C}_{2} \mathrm{H}_{2}$ reactions in the entire 500-2500 $\mathrm{K}$ range independent of pressure. However, the high temperature reversal of the equilibrium between $\mathrm{C}_{6} \mathrm{H}_{5}+\mathrm{C}_{2} \mathrm{H}_{2}$ and $\mathrm{C}_{8} \mathrm{H}_{7}$ will greatly hinder this route. Frenklach's original HACA route is shown to predominantly form a dehydrogenated naphthalene core (naphthyl radicals or naphthynes) for $T<2000 \mathrm{~K}$, while producing mostly a non-PAH diethynylbenzene product at higher temperatures. More quantitative conclusions on the role of HACA in the formation of a second aromatic 
ring await the inclusion of these and other related temperature- and pressure-dependent rate coefficients for all possible naphthalene formation pathways in flame modeling studies.

\section{Acknowledgements}

This material is based on work supported by the U.S. Department of Energy Department of Energy, Office of Science, Office of Basic Energy Sciences, Division of Chemical Sciences, Geosciences, and Biosciences (at FIU under Grant No. DE-FG02-04ER15570 and at ANL under Contract No. DE-AC0206CH11357). Software development was supported by the AITSTME project as part of the Predictive Theory and Modeling component of the Materials Genome Initiative. A.M.M. acknowledges partial support from ANL during his sabbatical leave in January-May, 2015. We thank Jim Miller and Raghu Sivaramakrishnan for helpful discussions.

\section{List of Supplemental Files}

Supplemental Material for this paper includes input files for RRKM-ME calculations using the MESS package, a table listing fitted modified Arrhenius expressions for the reactions considered appropriate for combustion modeling purposes together with a description of how they were obtained, a plot of the equilibrium constants for the $\mathrm{C}_{6} \mathrm{H}_{5}+\mathrm{C}_{2} \mathrm{H}_{2}$ reaction, comparison of the present rate predictions with those of Wang and Frenklach [17], and enlarged figures for each component of the rate and branching ratio plots from Figs 3 and 4, and plots of MEPs obtained from IRC calculations and used in variational TST calculations of rate constants.

\section{References}

[1] H. Richter, J.B. Howard, Prog. Energy Combust. Sci. 26 (2000) 565-608.

[2] C.J. Pope, J.A. Miller, Proc. Comb. Inst. 28 (2000) 1519-1527. 
[3] P. Lindstedt, L. Maurice, M. Meyer, Faraday Discuss. 119 (2001) 409-432.

[4] M. Frenklach, Phys. Chem. Chem. Phys. 4 (2002) 2028-2037.

[5] H. Richter, J.B. Howard, Phys. Chem. Chem. Phys. 4 (2002) 2038-2055.

[6] H. Richter, S. Granata, W.H. Green, J.B. Howard, Proc. Comb. Inst. 30 (2005) 1397-1405.

[7] G. Blanquart, P. Pepiot-Desjardins, H. Pitsch, Comb. Flame 156 (2008) 588-607.

[8] N. Hansen, J.A. Miller, S.J. Klippenstein, P.R. Westmoreland, K. Kohse-Hoinghaus, Comb. Expl. Shock Waves 48 (2012) 508-515.

[9] A. Matsugi, A. Miyoshi, Proc. Comb. Inst. 34 (2013) 269-277.

[10] Y. Wang, R. Abhijeet, S.H. Chung, Combust. Flame 160 (2013) 1667-1676.

[11] C. Saggese, N.E. Sanchez, A. Frassoldati, A. Cuoci, T. Faravelli, M.U. Alzueta, E. Ranzi, Energy Fuels 28 (2014) 1489-1501.

[12] A.W. Jasper, K.M. Pelzer, J.A. Miller, E. Kamarchik, L.B. Harding, S.J. Klippenstein, Science 346 (2014) 1212-1215.

[13] Y. Georgievskii, S.J. Klippenstein, Master Equation System Solver (MESS), unpublished (2015).

[14] Y. Georgievskii, J.A. Miller, M.P. Burke, S.J. Klippenstein, J. Phys. Chem. A 117 (2013) 1214612154.

[15] M. Frenklach, D.W. Clary, W.C. Gardiner, S.E. Stein, Proc. Comb. Inst. 20 (1984) 887-901.

[16] M. Frenklach, H. Wang, Proc. Comb. Inst. 23 (1991) 1559-1566.

[17] H. Wang, M. Frenklach, J. Phys. Chem. 98 (1994) 11465-11489.

[18] J. Appel, H. Bockhorn, M. Frenklach, Combust. Flame 121 (2000) 122-136.

[19] M. Frenklach, N.W. Moriarty, N.J. Brown, Proc. Comb. Inst. 27 (1998) 1655-1661.

[20] N.W. Moriarty, N.J. Brown, M. Frenklach, J. Phys. Chem. A 103 (1999) 7127-7135.

[21] J. D. Bittner, J. B. Howard, Proc. Comb. Inst. 18 (1981) 1105-1116.

[22] C.W. Bauschlicher, A. Ricca, Chem. Phys. Lett. 326 (2000) 283-287. 
[23] I.V. Tokmakov, M.C. Lin, J. Am. Chem. Soc. 125 (2003) 11397-11408.

[24] V.V. Kislov, N.I. Islamova, A.M. Kolker, S.H. Lin, A.M. Mebel, J. Chem. Theory Comput. 1 (2005) 908-924.

[25] J. Troe, J. Chem. Phys. 66 (1977) 4745-4757.

[26] A.W. Jasper, C.M. Oana, J.A. Miller, Proc. Combust. Inst. 35 (2015) 197-204 .

[27] A.W. Jasper, J.A. Miller, Combust. Flame 161 (2014) 101-110.

[28] S.J. Klippenstein, J.A. Miller, A.W. Jasper, J. Phys. Chem. A 119 (2015) 7780-7791.

[29] Y. Georgievskii, S.J. Klippenstein, J. Phys. Chem. A 107 (2003) 9776-9781.

[30] T. Yu, M.C. Lin, C.F. Melius, Int. J. Chem. Kinet. 26 (1994) 1095-1104.

[31] A. Fahr, S.E. Stein, Proc. Comb. Inst. 22 (1989) 1023-1029. 